Article

\title{
Analyzing Gaps in Hurricane Rain Coverage to Inform Future Satellite Proposals
}

\author{
Justin P. Stow ${ }^{1,2, *}$, Mark A. Bourassa ${ }^{1,2}$ and Heather M. Holbach ${ }^{1,2,3}$ \\ 1 Department of Earth, Ocean, and Atmospheric Sciences, Florida State University, Tallahassee, FL 32304, USA; \\ mbourassa@fsu.edu (M.A.B.); hholbach@fsu.edu or heather.holbach@noaa.gov (H.M.H.) \\ 2 Center for Ocean-Atmospheric Prediction Studies, Tallahassee, FL 32306, USA \\ 3 Hurricane Research Division-Atlantic Oceanographic and Meteorological Laboratory, Miami, FL 33149, USA \\ * Correspondence: jps15j@my.fsu.edu; Tel.: +1-908-420-7767
}

Received: 27 June 2020; Accepted: 16 August 2020; Published: 19 August 2020

check for updates

\begin{abstract}
This study assesses where tropical cyclone (TC) surface winds can be measured as a function of footprint sizes and wavelengths (Ka- Ku- and C-band). During TCs, most high-resolution surface observations are impeded by considerable 'rain contamination.' Under these conditions, high-resolution surface observations typically come from operational aircraft. Other techniques that provide high-resolution surface observations through rain are also hindered somewhat by rain contamination and are very sparse in space and time. The impacts of rain are functions of the remotely sensed wavelength and rain-drop size. Therefore, relative long wavelengths have been used to observe the surface, but at the cost of a larger footprint. We examine how smaller footprint sizes could be used to observe through gaps between moderate to heavy rainbands that circulate around the main low-pressure center of a TC. Aircraft data from the National Oceanic and Atmospheric Administration's (NOAA's) WP-3D turboprop aircraft will be used to create realistic maps of rain. Our results provide information on the satellite instrument characteristics needed to see the surface through these gaps. This information is expected to aid in developing hurricane-related applications of new higher-resolution satellites.
\end{abstract}

Keywords: tropical cyclone; rainband gap; satellite; rain rate; threshold; precipitation; wavelength

\section{Introduction}

Wavelengths from active aircraft instrumentation and satellites are attenuated much more in heavy rainbands than lighter ones, making observations of the surface difficult during heavy rain events [1]. Gaps between hurricane rainbands provide an exciting and potentially useful remote sensing opportunity to view the ocean surface during tropical cyclones (TCs). Unfortunately, two crucial problems arise when utilizing remote sensing to analyze the surface, as seen through these gaps. First, there is considerable rain contamination during heavy rain events that make it difficult to see through these bands [2], and this rain can also contaminate observations that have their nominal footprint outside the heavy rain, but radar sidelobes within the rain. This problem can be mitigated by observing with wavelengths much longer than the size of the rain-drops. Unfortunately, the resulting resolution is often too coarse to observe key features of a TC, such as the extent of certain wind radii or size of the eye, or areas of wind convergence and divergence that could be linked to intensity change. A second mitigation approach is to fly closer to the surface and measure at more frequencies to adjust for rain [3]. However, the data are only observed where research and operational aircraft are used to observe and study TCs. Synthetic Aperture Radar (SAR) observations [4] are also possible, but these are very sparse in space and time. Consequently, most wind measuring satellites either measure with 
long wavelengths over an area much larger than desired to capture the features of interest, or they measure with wavelengths too short to see the surface through the clouds or precipitation [5].

We will examine how well $3-5 \mathrm{~km}$ footprints see the surface in a TC with wavelengths that are highly sensitive to rain. Therefore, aircraft observations of rain will be used to estimate how well surface observations can be made through gaps in rain, within the range of capabilities that are considered plausible for simultaneously measuring surface winds and oceanic currents [6]. The National Academies of Sciences, Engineering, and Medicine recommended the launch of NASA Earth Explorer missions in the coming years [7], which might be a route through which such observations could be funded in the future. One of the proposed instruments would employ improved antenna technology and a moderately shortened wavelength to visualize the surface between rainy locations. To date, such observations have not been made from satellites. We will also examine longer wavelengths that are commonly used for scatterometry.

Remote sensing holds great potential, especially for TC structure analysis, as many of the observations that come from aircraft, such as dropsondes and flight-level data platforms (e.g., Stepped-Frequency Microwave Radiometer [SFMR], tail-Doppler radar [TDR]), provide greater detail than satellite platforms but are too sparse in data coverage [8]. Large periods without data make it cumbersome to draw any meaningful temporal conclusions about a TC's anatomy. Coverage by a single wide-swath instrument in a sun-synchronous orbit would also have sampling problems, but could provide a great deal of information when it passes over a storm. The funds available for satellite development are strongly dependent on the perceived success rate of mission goals; therefore, an assessment of capability must be made before serious consideration of such an activity as a mission objective. The primary motivation for such observations is relatively clear. Such a future study may also help improve understanding of the spatial scale of rainband gaps because this TC feature has had noticeable impacts on storm intensity, as evidenced by the work of Willoughby et al. [9], which analyzed the behavior of Hurricane Allen's rainbands and how they evolved into the eyewall. The lack of scientific research on the size of a hurricane's eyewall and rainband features illustrates the need for a more comprehensive study on the dynamics. Improvements to satellite capabilities plausibly would allow forecasters and meteorological analysts to construct more accurate representations of the atmosphere in these dynamic weather systems. This project examines whether a specific instrument design [6], as one case among the conditions examined, might advance our knowledge of the ocean surface under TCs.

\section{Background}

\subsection{The Tropical Cyclone Environment}

The distribution of gaps in the moderate to heavy rainbands that circulate around the main low-pressure center of a TC with respect to current satellite technology has not been studied in copious detail. To study this characteristic, it is important first to understand the traditional structure and dynamics of hurricane rainbands themselves. Marks [1] defined a classic rainband as a precipitation region with large vertical and small radial gradients of reflectivity and a pronounced "bright band" level indicative of stratiform precipitation. Senn and Hiser [10] estimated the lifetime of a spiral band to be a measure of the crossing angle that supports a clearly established identity apart from the main convective activity of the storm, which usually yields lifetimes of only one or two hours. The lifetime of a band could be extended by several hours if the band's head and tail protrude from the larger rain shield. Kepert [11] utilized a diagnostic TC boundary layer model to conclude that this atmospheric phenomenon is dependent on a number of factors, namely geographical location, temperature gradients, frictional convergence, boundary layer mean flow, and amplitude.

The aforementioned factors not only influence the relative strength of any given rainband, but also induce most of the precipitation in tropical cyclones to be organized in spiral circulations around the main low pressure center under a wide range of spatial scales. These spiraling bands form near the 
ring of maximum convergence close to the eye as a result of gravity waves or strong vertical upthrust at the wall cloud [11]. Additionally, the rainband typically remains in a quasi-conservative position relative to the quadrants in which it is formed, causing the rainband not to rotate about the storm center and remain in the quadrant of formation [10,11].

During this process, energy is released as the rainband oscillates around the wall cloud and one portion of a spiral band is created in a given quadrant at a given time [8]. Thus, both the gravity wave and the hurricane's upper level circular or outward wind field could provide the mechanism for the outward propagation of the spirals. The outward propagation of individual echoes and cross-band shear of the upper-level winds further contributes to the relative outward motion of rainbands away from the storm's center of circulation [10].

These types of bands have three classification schemes, namely inner, dynamic, and convective, and are often analyzed with regard to reflectivity, equivalent potential temperature, and radial and tangential wind components [1]. Moreover, a rotating rainband consists of a mix of stratiform and convective precipitation [12]. Generally, the upwind end of the band is mostly convective from the stronger observed vertical velocities and wind shear. Downwind, however, the band transitions into stratiform precipitation due to the weaker convective forcings. Barnes et al. [12] also concluded that there are substantially lower equivalent potential temperatures on the exit side of a rainband in contrast to that on the inflow side, which can be attributed to a partial mesoscale barrier. While the general structure described holds true for most cases, it is important to note that considerable spatial and temporal variability exists across any particular rainband or case study [11]. Senn and Hiser [10] found that due to the spiraling rainbands' relatively short lifetime, they frequently undergo dissipation and integrate into the main rain shield. One of the primary reasons for the enhanced dissipation of organized rainbands is the entrainment of stable air into the outer edges of the band [13]. This, in turn, returns the sub-cloud-layer air into the band that is unable to initiate moist convection and forces the zone of convergence outward away from the strongest cells near the bands' inner edges. These authors also postulated that changes in the vertical environmental winds may be partially responsible for the observed intensification or dissipation of the convergence zone adjacent to a hurricane's rotational airflow. Improved observations of surface vector winds would help address these questions, as well as several key points in Kepert's list of factors for diagnosing boundary layer behavior in a TC.

\subsection{Proposed Satellites}

The Winds and Currents Mission (WaCM) instrumentation has been demonstrated to accurately measure ocean vector winds and oceanic surface currents [14]. Using similar wavelengths but different view angles, the Sea surface KInematics Multiscale monitoring (SKIM) discussion [15] has been proposed to measure surface currents and wave characteristics, which also improve our knowledge of the TC boundary layer and air-sea coupling. Both approaches are able to measure true ageostrophic surface oceanic current vectors by utilizing Ka-band pencil-beam Doppler radars. A key difference between these missions was the angle at which WaCM viewed the surface was chosen to minimize wave dependencies, and the angles at which SKIM viewed the surface were chosen to minimize wind dependencies. Assumptions made in this paper are based on wind retrievals; however, they could also be used as a lower limit for SKIM retrievals in TCs. Both instruments are highly limited by the amount of rain in the main beam and sidelobes. That contrasts with planned C-band scatterometers, which are relatively insensitive to rain, but have much larger footprints.

Neither WaCM nor SKIM have mission plans associated with TCs. This is in part due to the sampling limitations of a single satellite, and in part due to the obvious difficulties with rain contamination. The instrument designs focused on non-rainy conditions, which are applicable to the vast majority of open ocean conditions. We will examine the tradeoffs of resolution and wavelength in the context of measuring surface winds in TCs. The impact of rain depends in part on the distance traveled through the rain. That distance is smaller for sensors such as SKIM [15] that observe at angles close $\left(\leq 11^{\circ}\right)$ to perpendicular to the surface, and worse for those with large angles $\left(\sim 56^{\circ}\right)$ for 
WaCM [14]. The WaCM zenith viewing angles are similar to those for the QuikSCAT-like pencil beam scatterometers; therefore, it is convenient to compare the impacts of rain for Ku-band (QuikSCAT) and Ka-band (WaCM). The planned C-band missions tend to have a fan beam design, with a zenith angle that increases with distance from the point below the satellite, ranging from $25^{\circ}$ to $65^{\circ}$. We will examine rain contamination only for a zenith angle of $55^{\circ}$; however, smaller angles will be less impacted by rain (they have a shorter path through the rain), and it will be seen that it is easy to infer the value of C-band over angles less than $55^{\circ}$.

\section{Data and Methodology}

This assessment will compare a variety of plausible satellite footprints (including sidelobes) to gaps in rain as seen in airborne radar observations. Section 3.1 will provide a basic overview of NOAA's WP-3D (P-3) turboprop aircraft Lower Fuselage (LF) radar with a brief discussion of the assumptions for the vertical dimension. Section 3.2 will discuss the process by which reflectivities were converted to rain rates and why certain thresholds were selected. Section 3.3 will present the methodology used to construct 4 footprint sizes consistent with the grid spacing of the NOAA radar data. The impact of rain is a function of the columnar integrated rain rate [16]. Radar reflectivity is a volume-averaged value, hence we need to know the vertical extent of the rain to convert the observed reflectivity to a columnar integrated rain rate. Two of the onboard radars are used to determine this value.

We selected examples from 5 storms: (1) Harvey (AL092017)-2017-08-25 16:54:53 UTC, (2) Irma (AL112017)-2017-09-05 09:45:00 UTC, (3) Jose (AL122017)-2017-09-18 01:57:11 UTC, (4) Maria (AL152017)-2017-09-24 08:14:29 UTC, and (5) Nate (AL162017)-2017-10-07 10:48:44 UTC. All 5 of these times occur when the aircraft is in the center of the storm. These specific case studies were selected to provide a diverse array of environmental conditions on a storm's intensity, including mid-level vertical wind shear, moisture content, land interaction, and dry air intrusions. Hurricanes Irma and Maria were chosen to represent axisymmetric storms that mirror a classic hurricane structure. Hurricanes Jose and Nate, on the other hand, were picked to highlight storms with strong vertical wind shear negatively impacting the storm's ability to keep or maintain strength. Hurricane Harvey's provides an example of a storm undergoing rapid intensification with simultaneous possible land interaction.

\subsection{NOAA Airborne Radars}

Aircraft radar data from NOAA's P-3 turboprop aircraft were used to provide the pattern of reflectivity and rain rates in TCs. The LF radar provided column integrated reflectivity over a large area centered on the aircraft. It is important to note that the LF radar system was changed in 2018, but data collected using the previous system were used in this study because all of the selected case studies occurred in 2017. The TDR provided a vertical profile of reflectivity but had very limited spatial coverage. This type of radar was not used extensively because of the LF radar system's superior spatial coverage and resolution. Table 1 presents the main characteristics of the transmitter, antenna, and radar in use for the LF radar and the TDR [17]. 
Table 1. Airborne radar parameters for the lower fuselage (LF) and tail radar systems aboard WP-3D flights [17].

\begin{tabular}{|c|c|c|}
\hline Parameter & LF Radar & Tail Radar \\
\hline Transmitter Frequency & $5370 \pm 6.7 \mathrm{MHz}$ & $9315 \pm 11.6 \mathrm{MHz}$ \\
\hline Transmitter Wavelength & $5.59 \mathrm{~cm}$ & $3.22 \mathrm{~cm}$ \\
\hline Transmitter Pulse & $6.0 \mu \mathrm{s}$ & $0.5 \mu \mathrm{s}$ \\
\hline PRF & 200 PPS & 1600 PPS \\
\hline Peak Transmitter Power & $70 \mathrm{~kW}(\mathrm{~min})$ & $60 \mathrm{~kW}(\mathrm{~min})$ \\
\hline Receiver Dynamic Range & $80 \mathrm{~dB}$ & $80 \mathrm{~dB}$ \\
\hline Gain (Main Beam) & $37.5 \mathrm{~dB}$ & $40 \mathrm{~dB}$ \\
\hline Gain (Sidelobe) & $23 \mathrm{~dB}$ down & $23 \mathrm{~dB}$ down \\
\hline Horizontal Beam Width & $1.1^{\circ}$ & $1.35^{\circ}$ \\
\hline Vertical Beam Width & $4.1^{\circ}$ & $1.9^{\circ}$ \\
\hline Antenna Stabilization & $\pm 10^{\circ}$ (pitch and roll) & $\pm 25^{\circ}$ (pitch and roll) \\
\hline Maximum Range & $371 \mathrm{~km}$ & $93 \mathrm{~km}$ \\
\hline
\end{tabular}

\subsubsection{NOAA WP-3D Lower Fuselage Radar}

For this study, the individual LF radar sweep files, which contain data from one $360^{\circ}$ scan of the LF radar, were used. The sweep files were chosen herein to have minimal contamination from inconsistencies in the viewing angle (i.e., when the aircraft turns) or interference from other instruments on the aircraft. When observing Harvey's LF sweep, for example, radiofrequency interference from one of the instruments aboard NOAA's P-3 aircraft was seen in the northwest quadrant of the LF sweep, which contributed an additional non-surface signal into the sensor's field of view. While this abnormality altered a portion of the reflectivities in the NW quadrant, all other aspects of this plot appeared to be unaffected by other kinds of interference.

HRD's MATLAB plotting function was converted to Python to aid in the processing of the LF sweep data files (formatted as two-dimensional .swp binary files). Complete documentation for the file headers and physical interpretations are listed on HRD's website [18]. These definitions were used for the meteorological computations described in Sections 3.2 and 3.3. Storms with sufficient TDR (used below) images and LF radar sweeps were selected to create a diverse array of strengths, sizes, structures to test for the various distributions of rainband gaps.

\subsubsection{NOAA WP-3D Tail Doppler Radar}

Unfortunately, HRD's .swp LF data files lacked information on the radar's vertical tilt and vertical distribution of reflectivity. In light of this, reflectivity was assumed to be constant over a height determined from HRD's TDR imagery for the same flight. Despite changes in precipitation type (snow, ice, water) with increasing altitude, the changes in precipitation types did not influence the measured reflectivities between 700 and $950 \mathrm{mb}$, the average levels NOAA's P-3 aircraft fly [19]. The 3 cross-sections from Hurricane Irma (Figure 1) had little vertical dependence on vertical reflectivity between the surface and the brightband. This layer greatly dominated the vertically averaged reflectivity that was available from the LF radar. Similar results were observed in the 4 additional case studies. Despite the lack of vertical information in the LF reflectivity data, the LF horizontal reflectivity fields will still allow us to determine the horizontal distribution of rainbands, and provide an estimate of a column average rain rate, which combined with an estimate of the layer thickness provides a column integrated rain rate, which is needed to assess the impacts on scatterometer observations. 
(a)
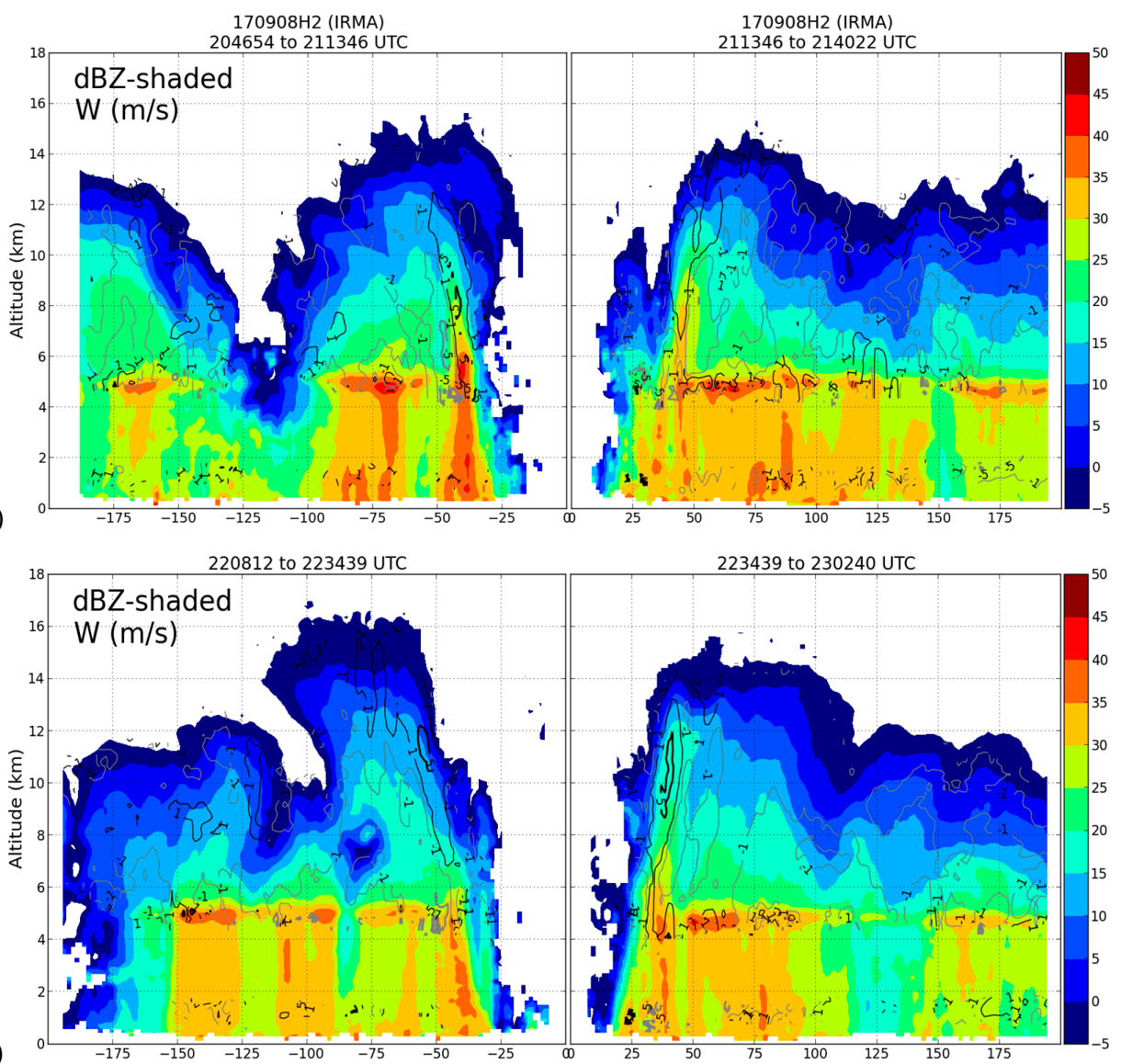

(b)

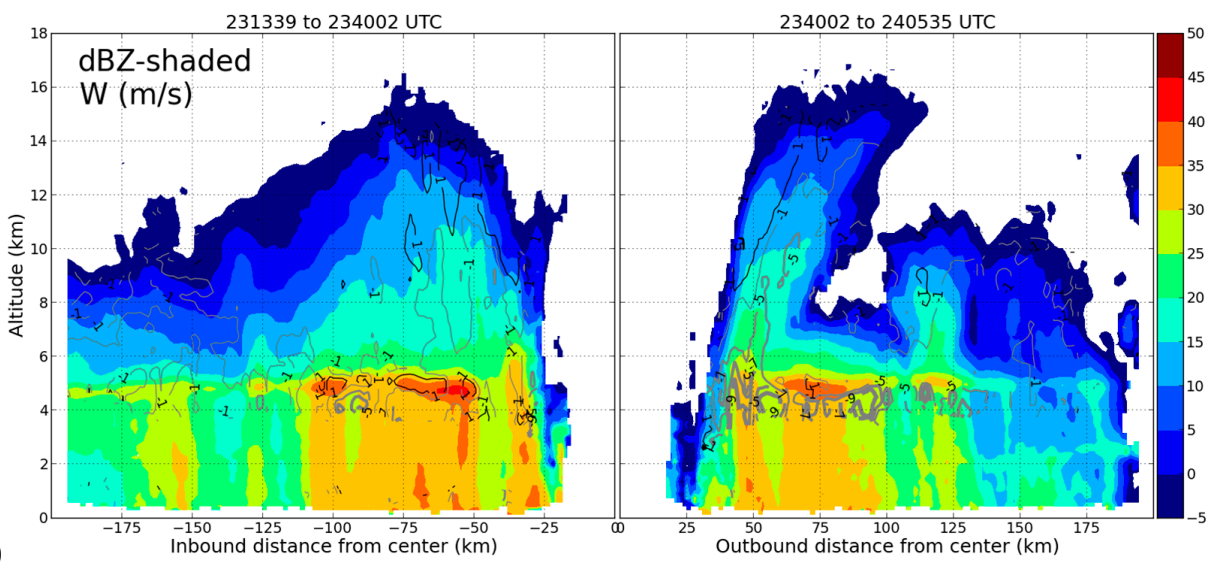

Figure 1. Vertical cross sections of Hurricane Irma (AL112017) for three different aircraft passes through the storm's rotating center on 8 September 2017: (a) 20:46:54-21:40:22 UTC, (b) 22:08:12-23:02:40 UTC, (c) 23:13:39-24:05:35 UTC [20]. These passes are used to determine the upper and lower bound approximations in the vertical dimension.

\subsection{Estimating Rain Rates from NOAA Radar Backscatter}

A relatively simple metric to identify hurricane rainband gaps was the application of a rain rate threshold, in units of millimeters per hour, to individual radar sweeps. This approach was a bit of an oversimplification: A columnar integrated rain rate would be a more accurate metric, but the LF radar's coarse vertical resolution and the similarity of rain rates in most of the atmospheric column meant that using a simple rain rate would be useful for this application. A good approximation for columnar integrated rain rate (CIRR) can be computed by multiplying a particular rain rate $(\mathrm{mm} / \mathrm{h})$ 
threshold by the height of the column $(\mathrm{km})$. Conversely, a threshold rain rate can be estimated from a threshold CIRR, by dividing the CIRR by the height of the rain column. This conversion should also account for the viewing angle and any change in path length through the rain: The CIRR and rain rate threshold are multiplied by the cosine of the viewing and for which the CIRR threshold was determined and divided by the cosine of the viewing angle under consideration. The HRD's LF radar data were stored as reflectivity, therefore, they must be converted to a rain rate. While there are many published conversion factors linking the two quantities [21,22], the Marshall-Palmer formula [23] is applied to the existing reflectivity data

$$
\mathrm{RR}=\left(\frac{10^{(\mathrm{dBz} / 10)}}{200}\right)^{0.625}
$$

where $\mathrm{dBz}$ is the reflectivity in $\mathrm{dBz}$ and $\mathrm{RR}$ is the rain rate in $\mathrm{mm} / \mathrm{h}$. This formula was chosen based on its commonality across various fields of radar meteorology and relatively simple computation with regards to computing power. There are many other Z-R relationships, contributing to the uncertainty in the resulting rain rates. For example, [17] has much smaller rain rates for very low reflectivities, and perhaps $20 \%$ greater for the most extreme rain rates. For Z-R relationships that indicate lower rain rates, we will be overestimating the impacts of rain and underestimating the locations where winds can be retrieved.

Our goal is to determine if the satellite radar's footprint fits inside a rain-free area. For many non-radar applications, a good approximation of rain-free locations is attained using a $0.5 \mathrm{~mm} / \mathrm{hr}$ threshold for determining rain-free regions; however, this cut-off should be a strong function of wavelength. Draper and Long [16] found that the $3 \mathrm{~km} \mathrm{~mm} / \mathrm{h}$ was a plausible threshold for wind speeds greater than $20 \mathrm{~m} / \mathrm{s}$ for Ku-band, which is typical of non-European scatterometers. At Ku-band (used by QuikSCAT and most other scatterometers), our threshold rain rate and respective correct units was $0.6 \mathrm{~mm} / \mathrm{hr}$, obtained by dividing the $3 \mathrm{~km} \mathrm{~mm} / \mathrm{h}$ by $5 \mathrm{~km}$. There were primarily 2 issues that modified the signal received by the radar: Attenuation of the signal passing both ways through the rain, and backscatter from rain (rather than off the surface). The backscatter effect at $C$-band, which was used by European scatterometers, was about the same as at Ku-band, while the former was much less sensitive to rain. For Ka-band, the backscatter was substantially smaller [24], and hence less of an issue compared to the larger attenuation at Ka-band. The most important frequency-dependent consideration, attenuation, had a much greater dependency on rain [25-27]. Assuming all other considerations are unchanged for a Ka-band instrument, a rain rate of just $0.1 \mathrm{~mm} / \mathrm{h}$ causes the same attenuation as our Ku-band threshold. For a C-band instrument, the threshold was $7.8 \mathrm{~mm} / \mathrm{h}$. From the perspective of seeing through rain, a lower frequency radar was strongly preferred. However, it was much more expensive to achieve the desired resolution at longer wavelengths. Thus, a compromise between the spatial resolution and penetrating power of the radar was expected to be needed for at least the near future.

A big antenna and longer wavelength were ideal for hurricane wind research. This combination was not a reasonable goal for the WaCM satellite mission because of cost and reduced accuracy of surface oceanic current measurements. To further extend this study, one could conduct a more expansive list of case study analyses that extend decades into the past. Furthermore, simulations could be constructed that predict multiple satellite viewing angles to better parameterize and represent a satellite's field of view under a wider range of differing storm structures. If vertical resolution reflectivity data were available, the other bounding case that incorporates more of the radar's actual angles of view could also be tested.

\subsection{Rain-Free Footprint Application}

Detailed images of storm rain rates and comprehensive 3-dimensional structure required multiple observations from multiple locations. The comparison of multiple aircraft viewing angles was 
preferable to characterize which angles yielded the most accurate imagery of surface features, such as wind speed and precipitation. We originally planned to identify 2 bounding cases that would bracket the real-world viewing angles of the satellite radar. The first case was to mimic a satellite looking straight down at the surface in order to provide an upper limit on the sizes of the rain-free regions. The other case was to block out areas accounting for the satellite's zenith view angle. This would be overly restrictive, as the satellite views any location on the surface from only 2 to 4 tight clusters of angles. For fan-beam antennas (e.g., ASCAT) there would be 3 azimuthal angles and a range of zenith angles. For conically rotating pencil beam radars, the zenith angles would be fixed for each beam, but the azimuth angles depended on the location across the swath. However, the radar data provided by NOAA was in a 2-dimensional format; hence we can look only at the first set of limiting cases that overestimate the visibility from the satellite. The grid spacing of the aircraft radar data had $2.75 \mathrm{~km}$ spacing, therefore, our simulated footprint size radii were limited to this grid spacing. The proposed footprint size (diameter) for WaCM was between 2.2 and $5.5 \mathrm{~km}$ [14]. To account for rain contamination of sidelobes, the relevant spatial scale for rain contamination was twice the length scale of the footprint. This factor of 2 had been seen in many assessments of land and ice contamination on estimates of ocean surface winds [28-30], although it was likely an overestimate [5], which compensates for our neglect of the zenith view angle in determining this area. Therefore, we examined footprints ranging from $2.75 \mathrm{~km}$ to $11 \mathrm{~km}$ in diameter.

For the purposes of this study, the constructed footprint sizes were dependent on the horizontal grid spacing of the data, which was $2.75 \mathrm{~km}$ per bin. Hence the 4 footprint sizes to be analyzed were $1.375,2.75,4.125$, and $5.5 \mathrm{~km}$, or rain-free areas with diameter $2.75,5.5,8.25$, and $11 \mathrm{~km}$, respectively. To maintain the typical geometric design of what a radar device would "see," the footprints were organized to be as circular as possible. These shapes were described in terms of integer offsets from the center of the area being tested. These integer $i$ 's and $j^{\prime}$ s represent the $i^{\prime}$ th or $j^{\prime}$ th index in the longitudinal or latitudinal position in the gridded aircraft radar data, as shown in Figure 2a-d. Once the rain rates for each point within this region were determined, one of 3 rain rate thresholds was applied to the entire viewing area. The thresholds of $0.1,0.6$, and $8.0 \mathrm{~mm} / \mathrm{hr}$ were chosen to represent Ka-, $\mathrm{Ku}-$, and C-bands, respectively. Only footprints that had rain rates below the rain threshold for every grid point were considered rain-free for the purposes of a satellite retrieval. Finally, for the 2 viewing areas with an even number of grid spacings in its diameter, namely the 2.75 and $5.5 \mathrm{~km}$ footprints, a longitudinal and latitudinal offset was applied to move the original centers (red highlighted text in Figure $2 b, d$ ) to the actual geographical center of the constructed footprints. An important note was that an edge buffer was included in the looping process to ensure that the edges of the footprint did not leave the 240 by 240 mesh grid of aircraft radar data.
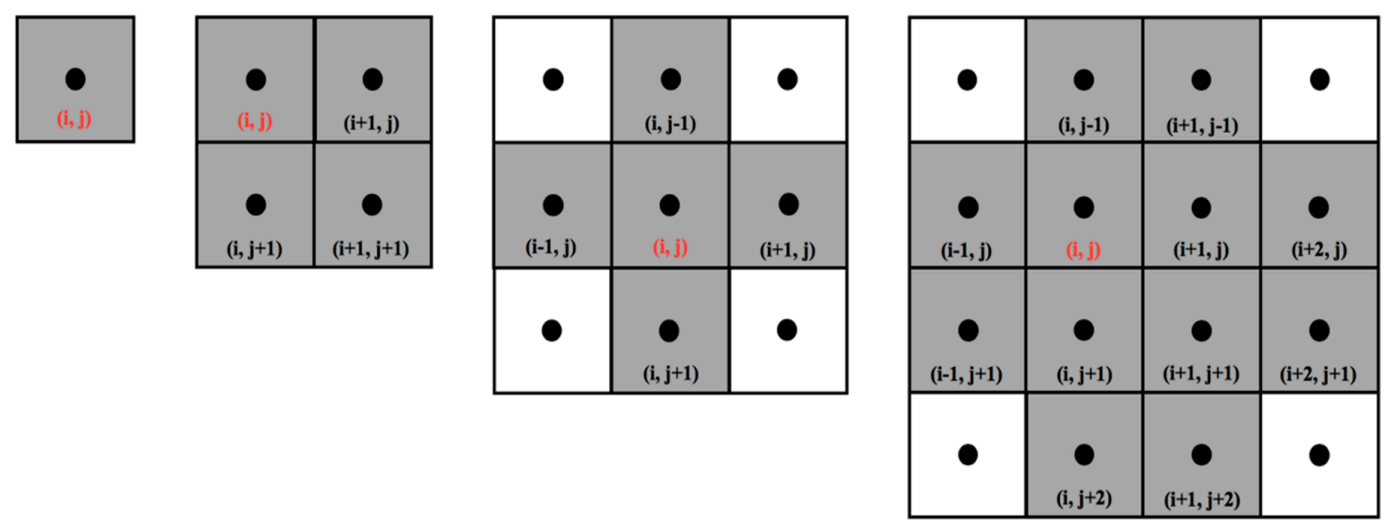

(a)

(b)

(c)

(d)

Figure 2. Shapes of the constructed viewing areas with diameters of (a) 2.75, (b) 5.5, (c) 8.25, and (d) $11 \mathrm{~km}$. The dots represent the center of a respective grid with the red text outlining the starting grid upon which steps were applied in the $i$ and $j$ directions to complete the relevant area. 


\section{Results}

Examining the LF reflectivities of several case studies under a variety of environmental conditions provides the ability to conduct preliminary analyses of the satellite radar's ability to view the surface between rain features. As shown in Figure 3a-e, larger, more axisymmetric storms with more organized convective activity circulating around the main area of low pressure result in a potentially larger spatial domain for rainbands to form. However, a smaller proportion of the computed rain rates exceeded one or more of the thresholds. These reflectivity plots seem to indicate that there were strong bunches of heavy precipitation spiraling around the storm center. While banding features were present in all storms, the number of bands appeared to be a function of the storm's intensity and overall structure. As an illustration, Irma (Figure 3b) and Maria (Figure 3d), storms, which contained large wind fields, axisymmetric rotation, and organized precipitation regions, presented banding features extending farthest radially from the storm center. There were fewer rainband gaps with these low vertical wind sheared storms as the regions of stratiform precipitation were too strong to meet any of the rain rate thresholds. The LF reflectivities of Hurricanes Jose (Figure 3c) and Nate (Figure 3e) demonstrated evidence of strong vertical wind shear as their southwest and northwest quadrants, respectively, were devoid of reflectivities greater than 20-25 dBz. These storms also appeared to possess larger rainband gaps and thus presented more opportunity to see the surface between precipitation structures.

Reflectivities ranging from 10 to $20 \mathrm{dBz}$ were found in the outer peripheries of all quadrants for all storms. This signal was a result of sea clutter, where light rain was being falsely presented. Sea clutter tends to appear as a very smooth overall response with increased levels of total radar return caused by precipitation, waves, and sea spray [28]. This is a problem for radar systems because the intended targets could be masked by other intermediate objects that cause the reflected signal to rise suddenly and remain high over a large range. False return signals to the radar negatively impact precipitation metrics, such as rain rates, and make it more cumbersome for forecasters to analyze true areas of precipitation or cloud cover in the atmosphere.

Figure 4a-e present two similar sets of plots. The left figures demonstrate that the rain-free regions and observable footprint areas were identical for the smallest footprint $(1.375 \mathrm{~km})$. In other words, the footprint can see the surface wherever the rain rate was less than the set threshold for all points in that footprint limited by the resolution of the LF radar sweeps. The right figures show the 1-minute sustained marine surface winds for the five selected case studies. A diverse array of platforms (aircraft, buoys, scatterometers, weather stations, and ships) were assimilated to construct wind fields using Risk Management Solutions' HWind Quality Control (QC) application [29]. This tool allows for an analyst to flag erroneous data and improves historical analyses of TCs. These figures illustrate both wind and rain patterns, indicating that there is not a clear relationship between the two variables.

After conducting historical re-analyses, the rain and wind structures for each respective storm were found to be similar. Generally, the radius of maximum winds for more symmetric storms, namely Harvey (Figure 4a), Irma (Figure 4b), and Maria (Figure 4d), varies between 11 and 19 nautical miles. The same radii for Jose and Nate were larger at 36 and 32 nautical miles, respectively. These two heavily sheared storms contained nearly no winds stronger than tropical storm force upshear, which was expected given that precipitation, convective activity, and general circulation around the low-pressure center were inhibited by strong vertical wind shear [9]. Harvey's wind field (Figure 4a) demonstrates that although there is slight land interaction in the storm's western quadrants, the regions of strongest winds still align with the precipitation in the outer peripheries.

While these first two sets of plots provided a synoptic-scale overview of the precipitation and winds for each case study, Figures 5-7 present the results of applying the four footprints. Generally, the regions of rainband gaps as determined by the reflectivity plots (reflectivity less than $20 \mathrm{dBz}$ ) in the stratiform regions of each storm do not have as strong a rain-related signal, even for the relatively rain-sensitive Ka-band. Moreover, Hurricanes Jose (Figures 5c, 6c and 7c) and Nate (Figures 5e, 6e and 7e) have the greatest percentage of rain-free areas in comparison to the other three storms for any given rain rate threshold or footprint size. 


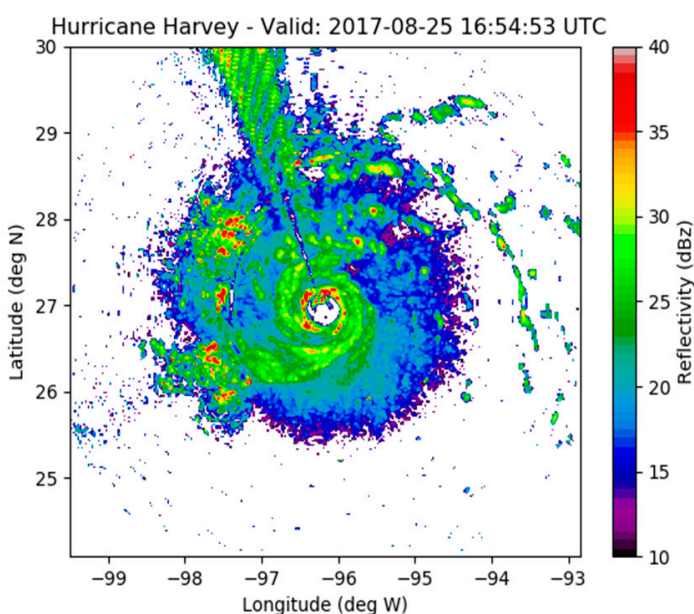

(a)

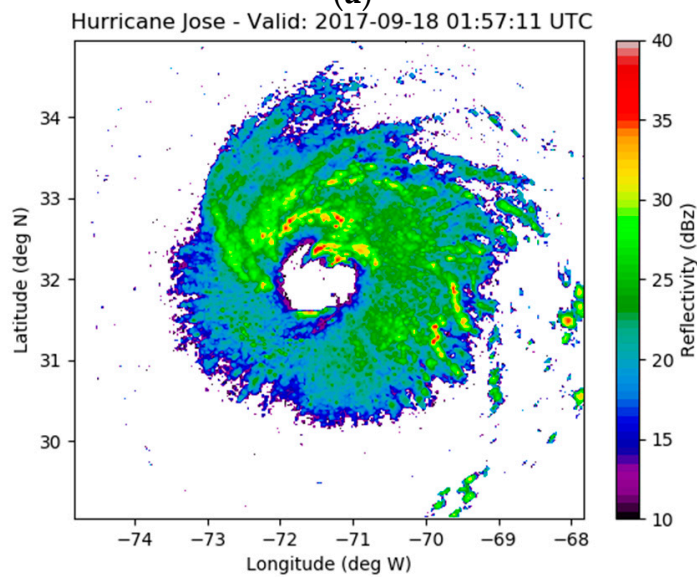

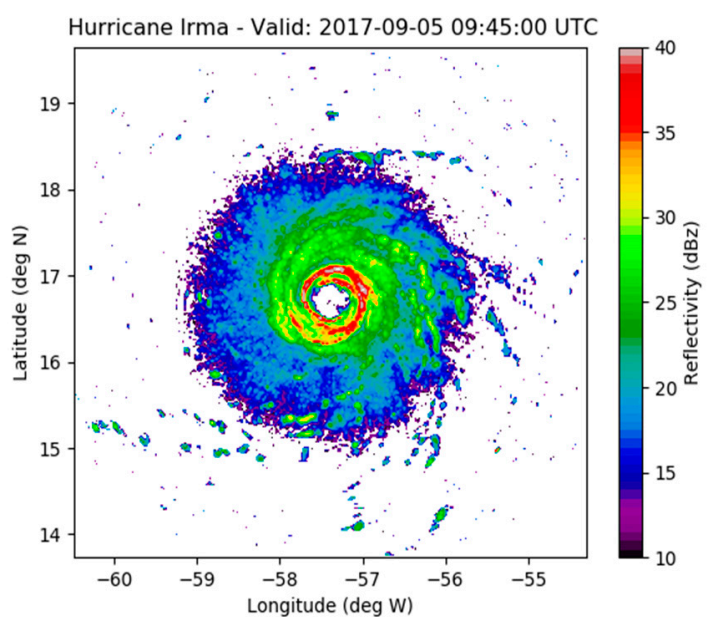

(b)

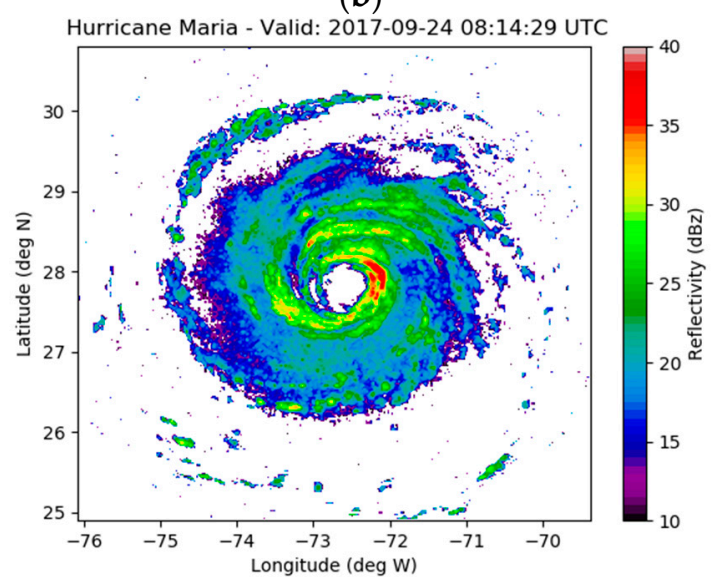

(d)

(c)

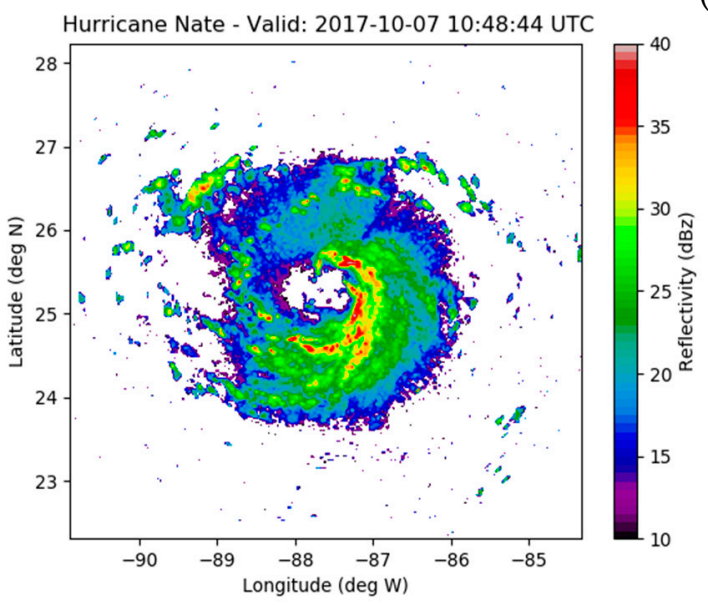

(e)

Figure 3. Lower fuselage reflectivities for the following case studies: (a) Harvey-AL092017, (b) Irma-AL112017, (c) Jose-AL122017, (d) Maria-AL152017, and (e) Nate-AL162017. Harvey's reflectivity plot shows partial obstruction of the radar signal from the aircraft itself, which is known as radiofrequency interference. 
(a)
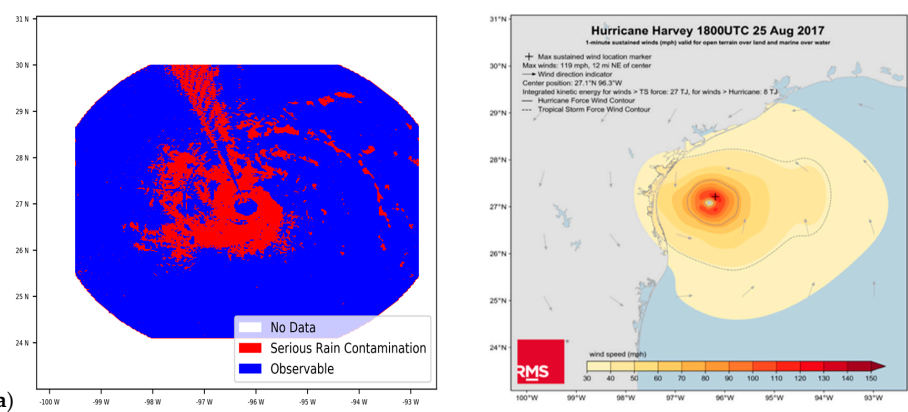

(b)
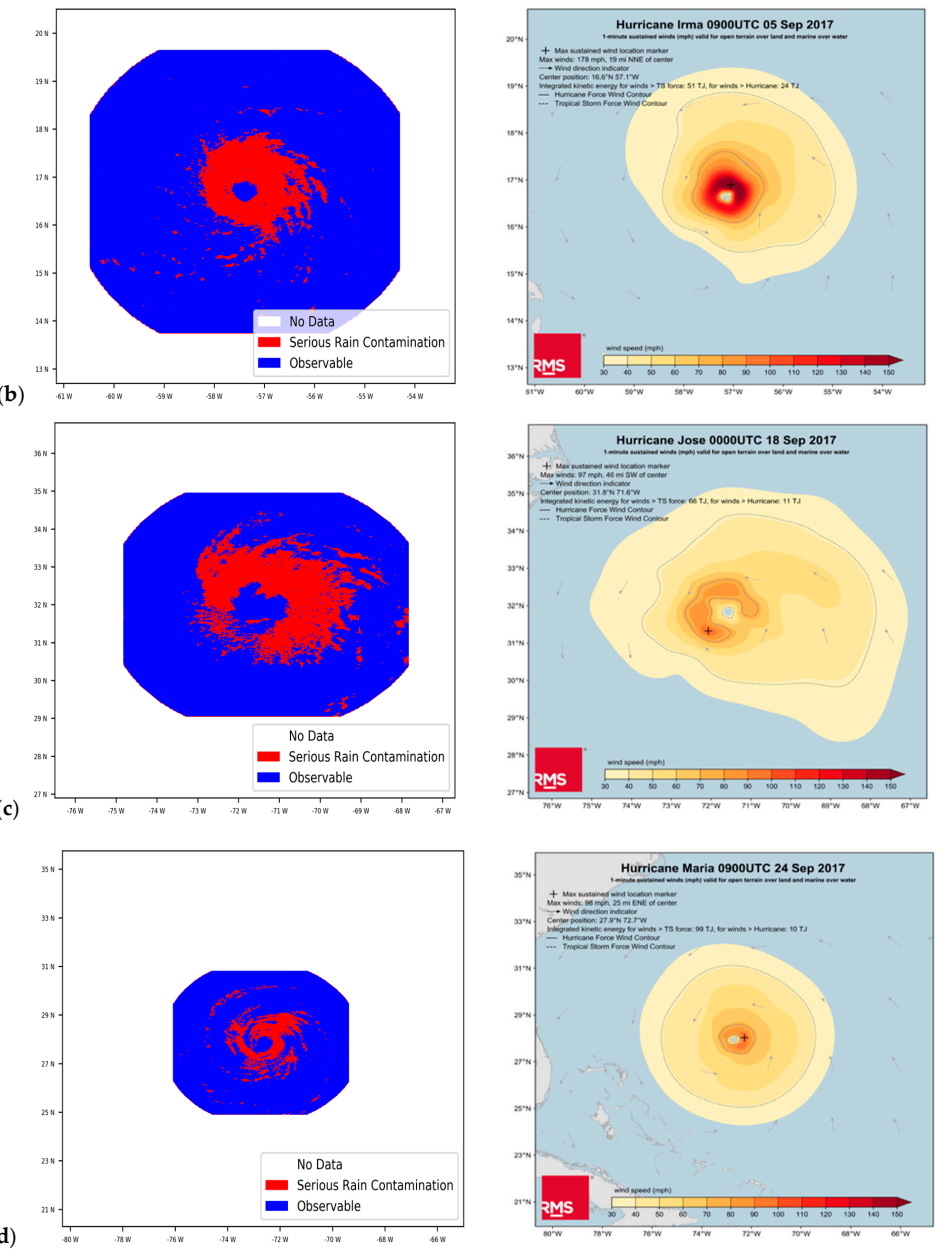

(d)
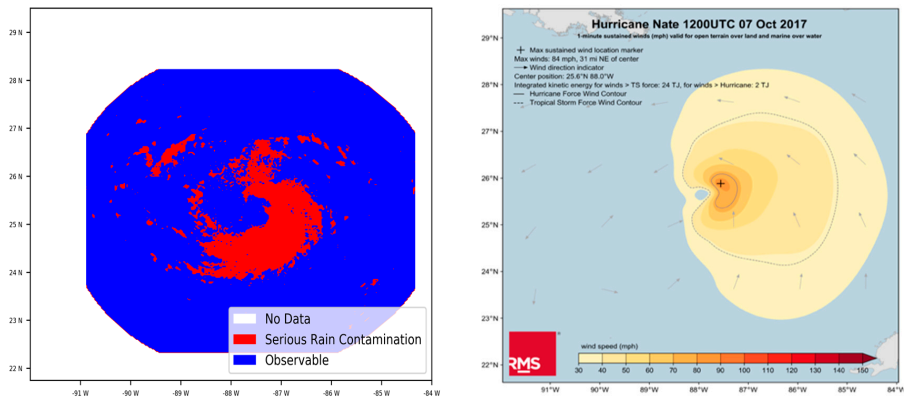

Figure 4. (Left) $0.6 \mathrm{~mm} / \mathrm{hr}$ rain rate threshold applied to reflectivity data using a $1.375 \mathrm{~km}$ footprint size where the red shaded regions indicate areas of rain while the blue translates to predicted rain-free observable areas. (Right) Risk Management Solutions' HWind historical wind fields for (a) Harvey-AL092017 2017-08-25 16:54:53 UTC, (b) Irma-AL112017 2017-09-05 09:45:00 UTC, (c) Jose-AL122017 2017-09-18 01:57:11 UTC, (d) Maria-AL152017 2019-09-24 08:14:29 UTC, and (e) Nate-AL162017 08:14:29 UTC. 
(a)
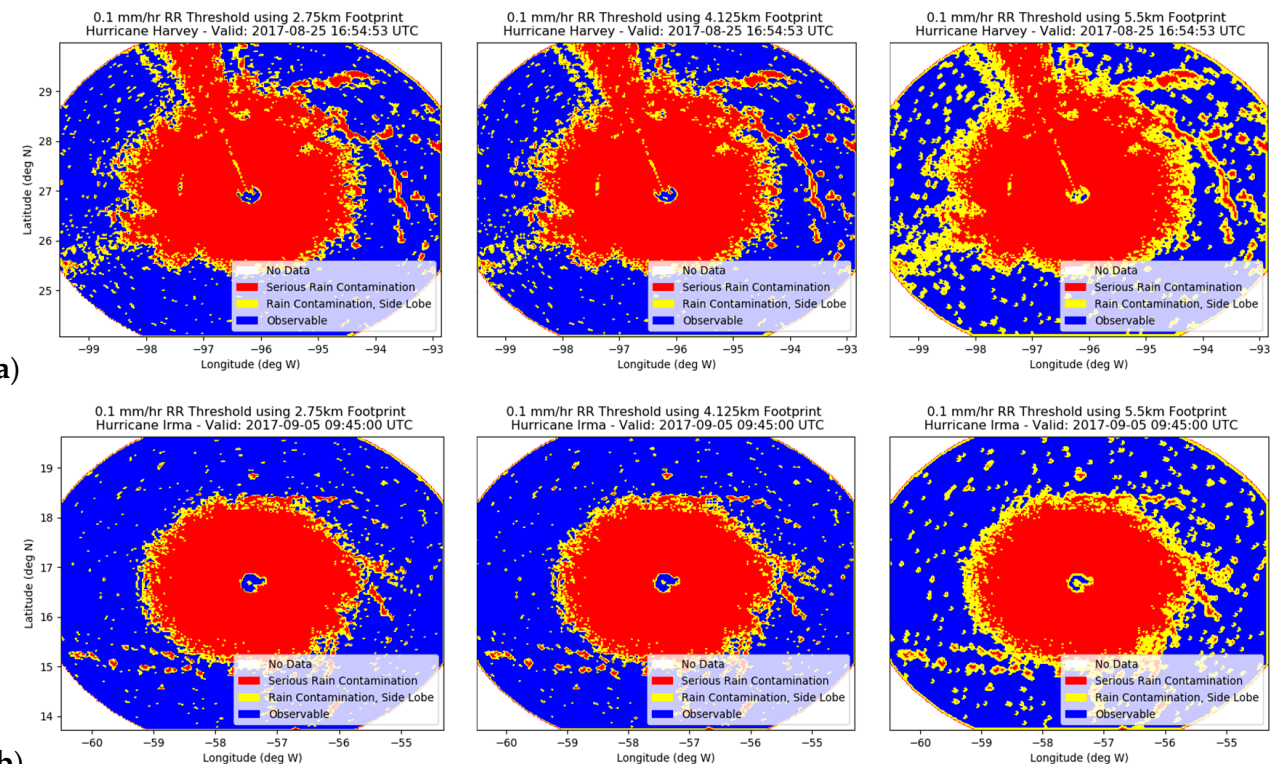

b)
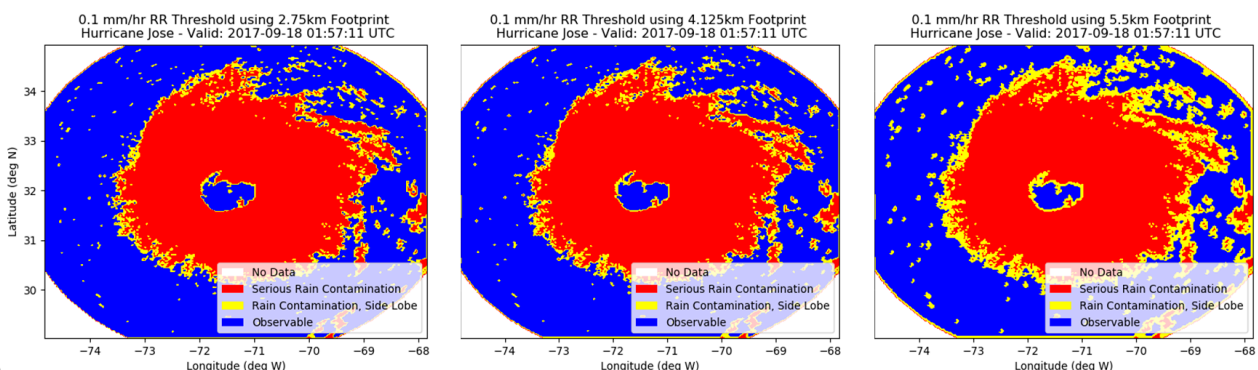

(c)
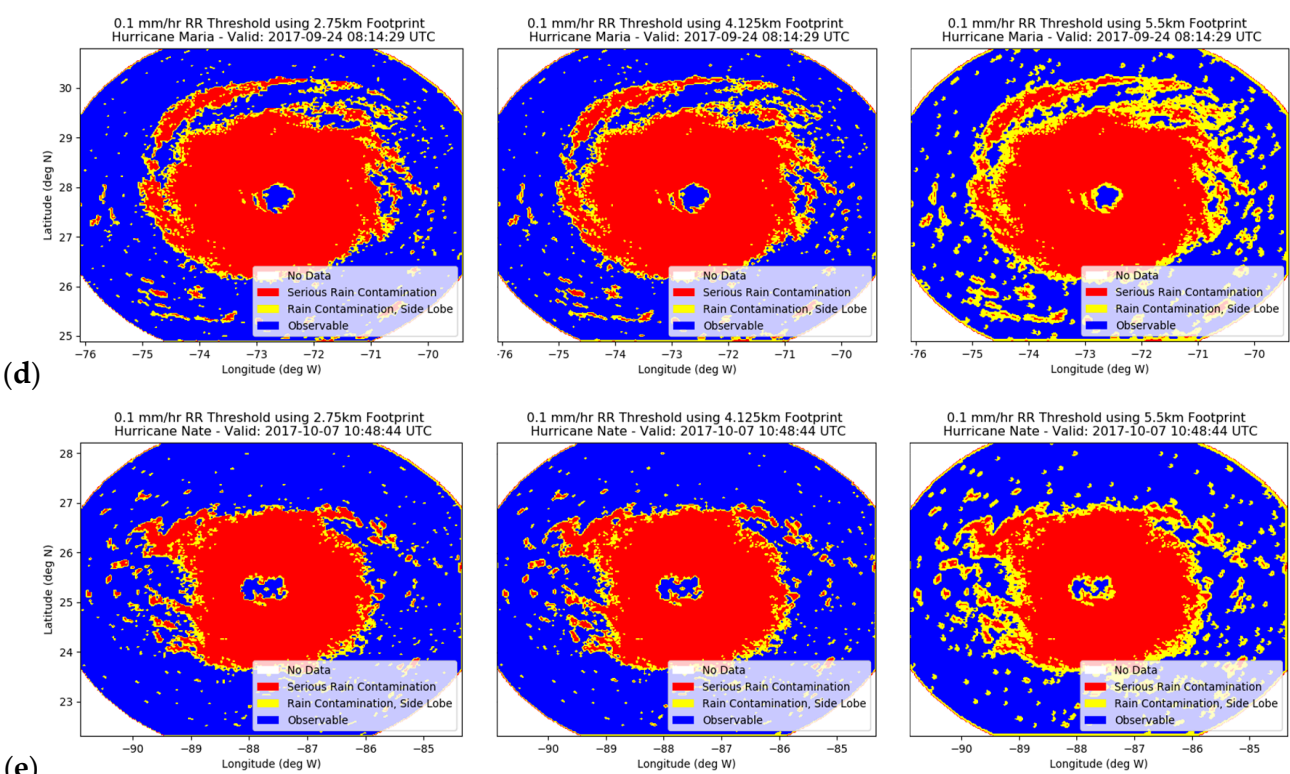

Figure 5. $0.1 \mathrm{~mm} / \mathrm{h}$ rain rate threshold applied to data for (a) Harvey-AL092017, (b) Irma-AL112017, (c) Jose-AL122017, (d) Maria-AL152017, and (e) Nate-AL162017. Rain rates at or below the threshold and surface observable (blue), rain rate at or below the threshold but surface not observable due to problems somewhere in the footprint (yellow), and rain rate exceeds the threshold (red). 
(a)
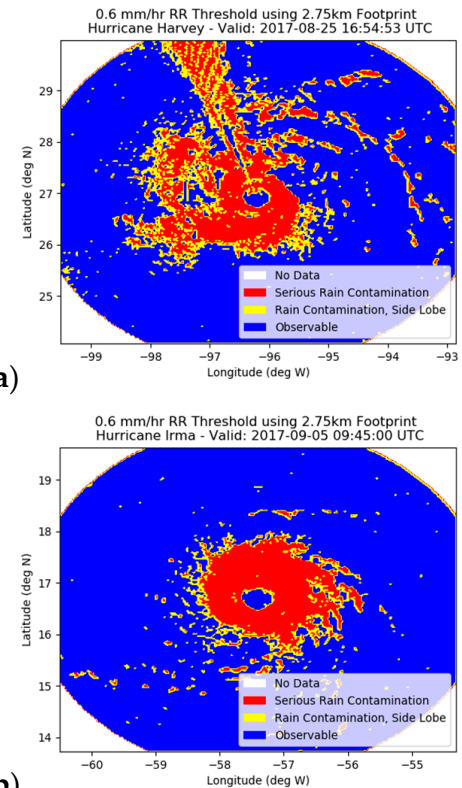

(b)

(c)
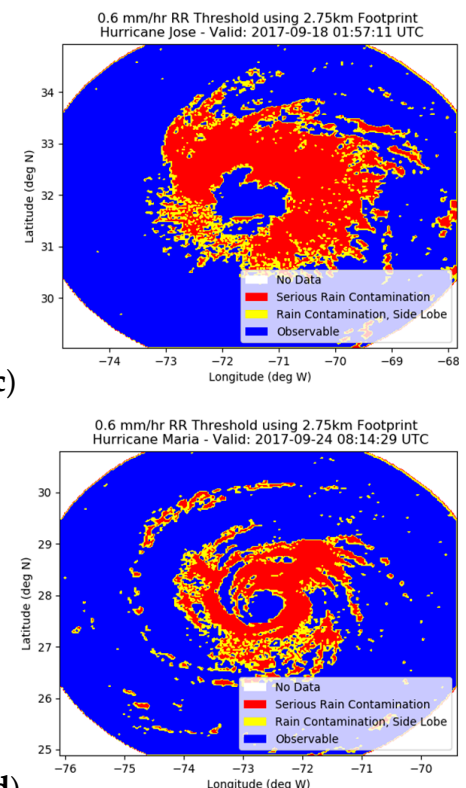

(d)

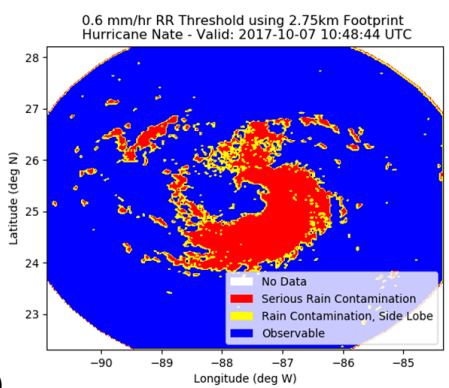

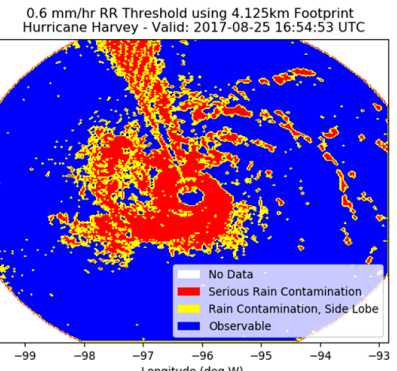
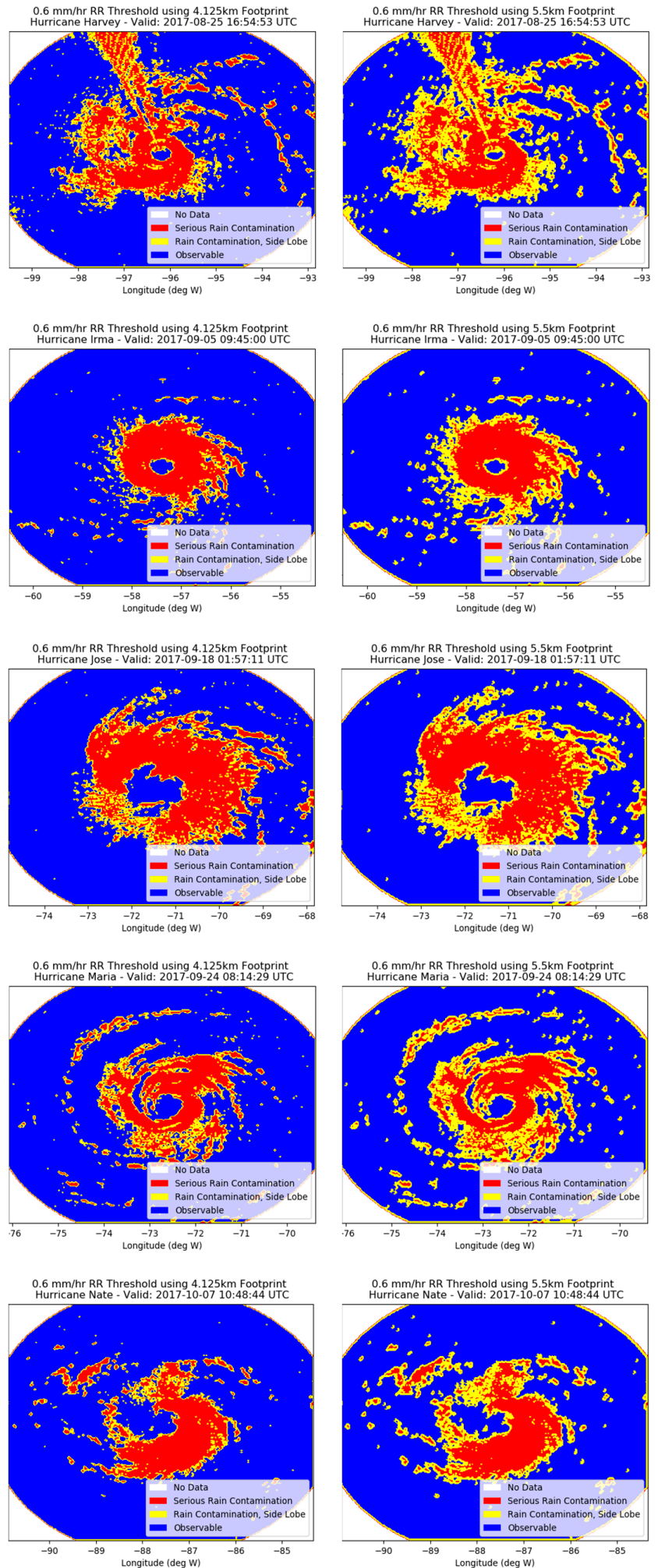
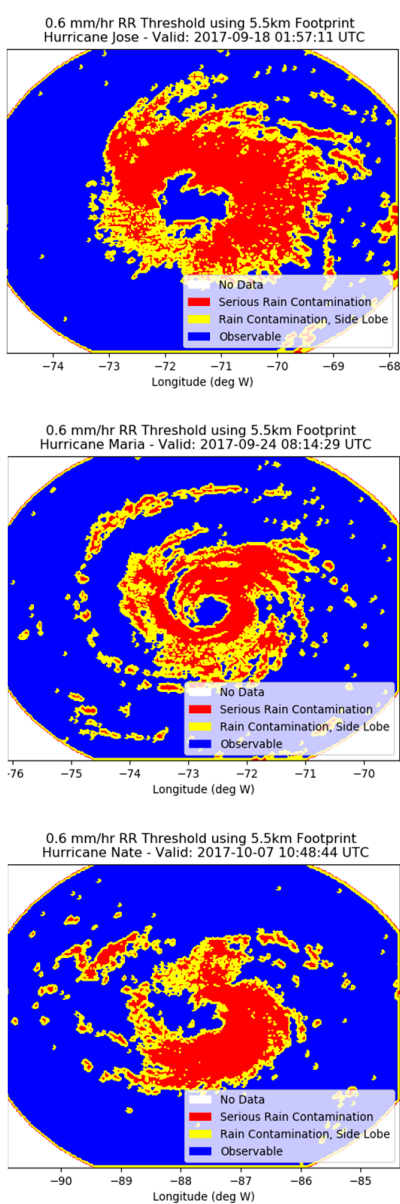

Figure 6. $0.6 \mathrm{~mm} / \mathrm{h}$ rain rate threshold applied to data for (a) Harvey-AL092017, (b) Irma-AL112017, (c) Jose-AL122017, (d) Maria-AL152017, and (e) Nate-AL162017. Rain rates at or below the threshold and surface observable (blue), rain rate at or below the threshold but surface not observable due to problems somewhere in the footprint (yellow), and rain rate exceeds the threshold (red). 
(a)
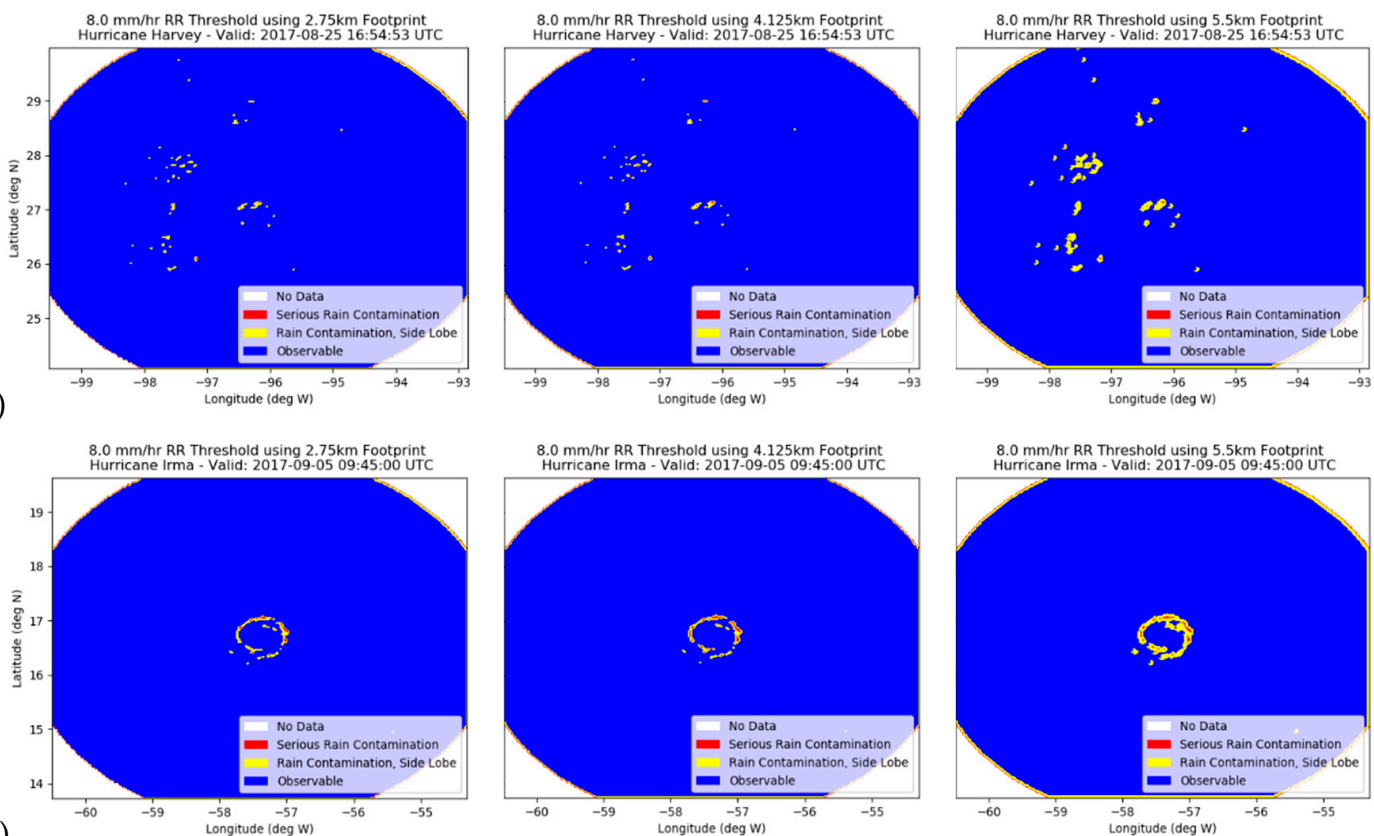

(b)
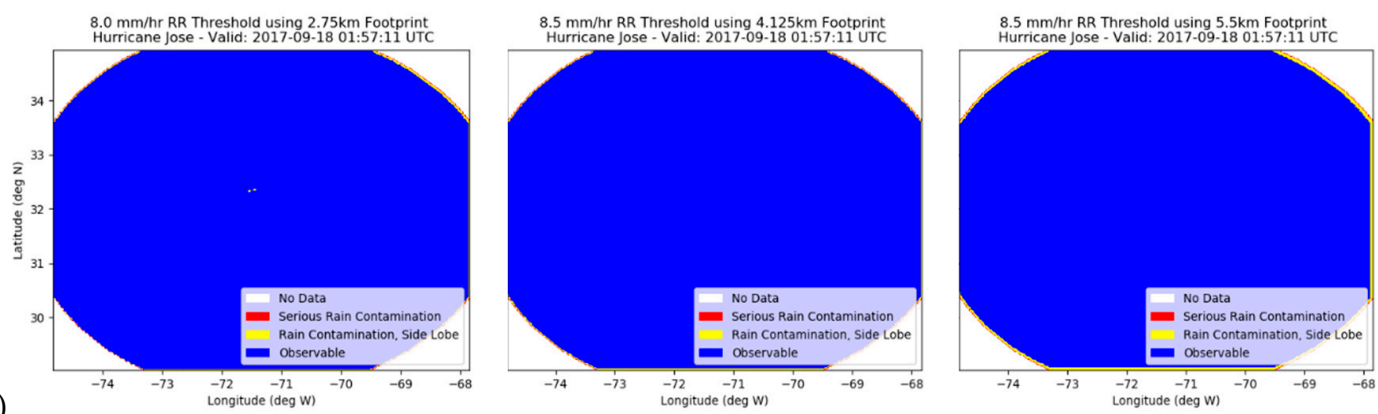

(c)
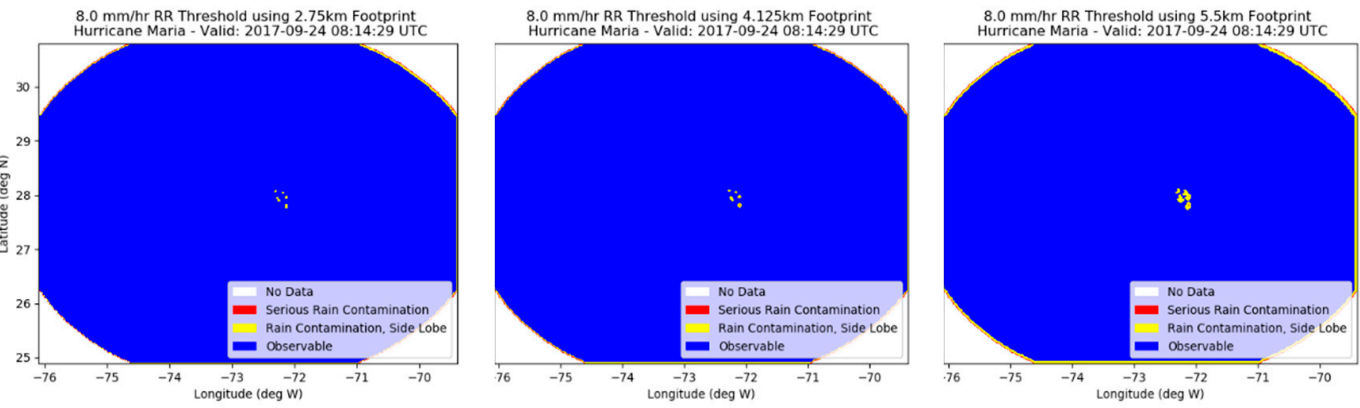

(d)
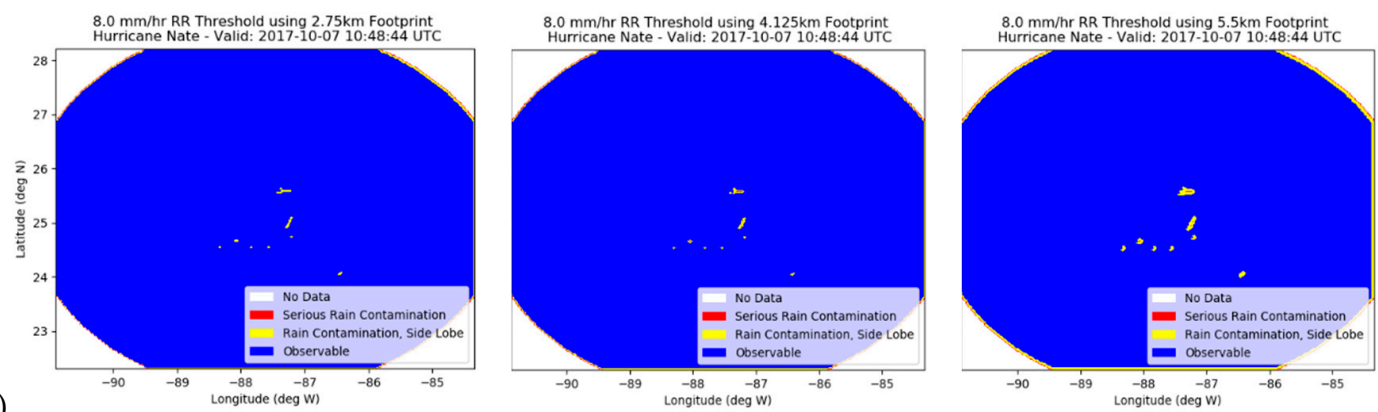

Figure 7. $8.0 \mathrm{~mm} / \mathrm{h}$ rain rate threshold applied to data for (a) Harvey-AL092017, (b) Irma-AL112017, (c) Jose-AL122017, (d) Maria-AL152017, and (e) Nate-AL162017. Rain rates at or below the threshold and surface observable (blue), rain rate at or below the threshold but surface not observable due to problems somewhere in the footprint (yellow), and rain rate exceeds the threshold (red). 


\section{Discussion}

The spatial differences in results vary across all rain rate thresholds and quickly become more apparent with higher rain rate thresholds, as evidenced by the significantly lower percentages of rain contamination in Tables 2-5 for $\mathrm{Ku}$ - and C-bands. The important takeaway is the change in these percentages, rather than the individual percentages. These percentages were computed by dividing the total number of grid points consisting of serious or side lobe rain contamination by the total number of grid points within a certain distance from the storm. If the frequency would be left unchanged in the design of future instruments, a higher threshold could be applicable only if there is greater power in the satellite's radar or a better antenna. If the footprint size could remain unchanged, then there would be clear and large advantages to working with longer wavelengths and viewing angles closer to nadir. However, a viewing angle closer to nadir would reduce the spatial/temporal coverage of the satellite, which would have a large impact on TC applications. Sufficiently fine footprint size is needed to observe small-scale features and to calculate spatial derivatives of surface wind vectors. The footprints of several current satellites, such as $40-60 \mathrm{~km}$ for SMOS and $25 \mathrm{~km}$ for CYGNSS, are too large to observe the desired localized wind and precipitation patterns [5], much less calculate spatial derivatives on the spatial scales that are desired, and could be linked to intensification and weakening of the storm. For measurements of wind speed alone, footprint size is less important for longer wavelengths. However, the ability to retrieve wind speed with $\mathrm{Ku}$ - or Ka-band instruments is very sensitive to both the rain rate threshold and footprint size. When examining regions near heavy rain features, Figures $5-7$ show that the spatial extent of observable rain-free regions decreases exponentially with a linear increase in footprint. These rain-free but unobservable regions are yellow in Figures 5-7, distinct from rainy regions (red) and observable regions (blue). Thus, the largest decrease in rain-free regions is observed between the 8.5 and $11.0 \mathrm{~km}$ (diameter) footprints. The largest footprint (Figures $5-7$ ) is associated with the smallest fraction of observable regions in all five case studies. The key findings are that considerable radar power or a longer wavelength is desirable to increase the rain threshold to the point (around $0.8 \mathrm{~mm} / \mathrm{h}$ ) where much more of the rain covered surface becomes visible to the satellite radar. Smaller footprints, which also require more power, or in contrast a shorter wavelength, are also highly desirable to see the most interesting parts of the storm, and to better understand TC boundary layer dynamics. Despite these conflicting needs, it is clear that the surface is likely to be visible in much of the eye, where such observations could be informative about intensity changes [30].

Table 2. Percentage of Rain Contamination (Serious and Side Lobe) using 2.75 km Footprint.

\begin{tabular}{cccc}
\hline Storm & Ka-Band (\%) & Ku-Band (\%) & C-Band (\%) \\
\hline Harvey & 38.581414 & 16.802261 & 0.162331 \\
Irma & 29.070700 & 11.328826 & 0.196707 \\
Jose & 38.411000 & 22.161955 & 0.003819 \\
Maria & 34.110363 & 13.342632 & 0.017196 \\
Nate & 27.912528 & 12.463712 & 0.042016 \\
\hline
\end{tabular}

Table 3. Percentage of Rain Contamination (Serious and Side Lobe) using $5.5 \mathrm{~km}$ Footprint.

\begin{tabular}{cccc}
\hline Storm & Ka-Band $\mathbf{( \% )}$ & Ku-Band (\%) & C-Band (\%) \\
\hline Harvey & 49.448073 & 26.607081 & 1.455253 \\
Irma & 36.929452 & 16.468049 & 1.388411 \\
Jose & 45.859434 & 29.893048 & 0.928189 \\
Maria & 42.825206 & 20.779195 & 0.970651 \\
Nate & 35.166157 & 17.910618 & 1.048510 \\
\hline
\end{tabular}


Table 4. Percentage of Rain Contamination (Serious and Side Lobe) using 8.25 km Footprint.

\begin{tabular}{cccc}
\hline Storm & Ka-Band (\%) & Ku-Band (\%) & C-Band (\%) \\
\hline Harvey & 51.974714 & 28.971391 & 2.127497 \\
Irma & 39.058859 & 18.156296 & 2.033917 \\
Jose & 47.729182 & 31.860198 & 1.478227 \\
Maria & 45.089422 & 22.896285 & 1.534316 \\
Nate & 37.226890 & 19.619938 & 1.629106 \\
\hline
\end{tabular}

Table 5. Percentage of Rain Contamination (Serious and Side Lobe) using $11.0 \mathrm{~km}$ Footprint.

\begin{tabular}{cccc}
\hline Storm & Ka-Band (\%) & Ku-Band (\%) & C-Band (\%) \\
\hline Harvey & 61.678316 & 37.254115 & 4.096482 \\
Irma & 47.387418 & 24.137733 & 3.697337 \\
Jose & 54.436592 & 38.294499 & 2.759740 \\
Maria & 53.691531 & 30.157062 & 2.875649 \\
Nate & 45.261650 & 25.412528 & 3.048128 \\
\hline
\end{tabular}

The findings in this paper are based on a number of assumptions, the weakest of which is that the threshold columnar integrated rain rate found in [16] remains applicable for the more extreme TC conditions. It has been argued by Paul Hwang (personal communication, 2019) that the key physical assumptions regarding the surface waves, to which these microwave radars respond, do apply at these conditions. However, if this application is a key mission goal, it would be prudent to test the ability of an airborne version of these instruments to retrieve winds in these extreme conditions. Such observations would also address concerns about the applicability of the Z-R relationship that we have used in this analysis.

The importance of issues with the airborne data is also the dependence on the rain rate threshold, and hence on the frequency of the satellite radar. For instance, rain contamination from sea clutter are significantly reduced when applying higher rain rate thresholds. That finding suggests that some of the locations we have identified as blocked by rain could have been erroneously designated as such because of relatively large ground clutter. This is an issue that could be addressed when (and if) the NOAA radar data are reprocessed.

\section{Conclusions}

This rainband gap analysis has provided a brief introduction into the remote sensing involved in observing surface characteristics under a TC, based on observations of scatter due to rain from HRD's LF radar sweeps. It informs designers of satellite missions regarding options and needs for high resolution (non-SAR) radar observations of the ocean surface. One strength of the chosen approach was the ability to select and visualize any state of the storm sampled by the LF data sweeps. This methodology and dataset provide a wide range of environmental conditions and rain rates. This study confirms that having an ability to control many of the control parameters, such as rain rate thresholds and footprint size, facilitates a future analyst's ability to better understand the spatial scale of rainband gaps in TCs and the behavior of winds in those gaps. The presented results strongly show the expected result that, for the Ka- and Ku-band, smaller footprints will yield the best observations (meaning covering the greatest area) of the rain-free regions for a TC. The coverage that can be achieved for C-band is almost independent of footprint size because rain is rarely a barrier to the observations. For any frequency that is used for remote sensing, the choice of 'best' footprint size will also be a function of the application. If spatial gradients are important, then the finer resolution is highly desirable. If those gradients are to be examined under and around rain bands, then lower frequency observations are needed to penetrate the rain. On the other hand, line integral methods [31] can be used to calculate surface inflow into rainy areas, using only observations from surrounding rain free areas. 
This research could be useful for planning TC-related goals for future satellites. These results provide thresholds for designing an instrument that would observe surface winds and oceanic currents in a TC environment, which should provide numerous benefits to forecasting and operational applications, ideally without compromising other goals of the satellite mission. Rodriguez [32] proposed a new design approach for a sensor aimed at improving the measurement of wind stresses and surface oceanic currents using a large swath $(\sim 1800 \mathrm{~km})$, high spatial resolutions (less than $11 \mathrm{~km}$ ), and continuous spatial coverage without any statistically significant gaps within the swath, except areas of substantial rain, land, and ice. Our findings support using the instrument design presented in Rodriguez's analysis, with the lower range of footprint sizes and ideally more power [33]. The results presented herein strongly indicate that such a design would likely be useful for operational applications related to TCs [32] and to improve our understanding of TC intensification. The largest $11 \mathrm{~km}$ footprint does provide sufficient rain-free coverage in the eye to make practical conclusions about storm winds, but substantially more coverage would occur with smaller footprints. As shown in Figures 5-7, all of the tested rain rate thresholds demonstrate regions of significant rain contamination within all quadrants, both radially and azimuthally, for each case study. While the specific distribution of hurricane rainband gaps, structure, and organization are all dependent on the specific case study being analyzed, the input parameters for yielding the most accurate images has been shown to be independent of the TC structure. This analysis helps demonstrate that the ideal parameters to test for rain-free areas using this radar system are a rain rate threshold between $0.6-0.8 \mathrm{~mm} / \mathrm{h}$ and any footprint size less than $8.25 \mathrm{~km}$ as both increasing wavelength and decreasing footprint size are significant in improving the area that can be observed. These parameters are shown to produce reasonably low sensitivity to the aforementioned problems, such as sea clutter contamination, coarse grid spacing, and radio frequency interference. More generally, this satellite instrument is predicted to be more useful for highly sheared or more antisymmetric storms as a larger fraction of the surface can be detected. As expected from SAR observations, a small footprint can be used to work around many of the problems associated with high sensitivity to rain.

Author Contributions: Conceptualization, J.P.S., M.A.B. and H.M.H.; data curation, J.P.S.; formal analysis, J.P.S., and M.A.B.; funding acquisition, M.A.B. and H.M.H.; investigation, J.P.S., M.A.B. and H.M.H.; methodology, J.P.S., M.A.B. and H.M.H.; project administration, M.A.B.; resources, J.P.S.; software, J.P.S.; supervision, M.A.B.; validation, J.P.S., M.A.B., H.M.H.; visualization, J.P.S.; writing-original draft preparation, J.P.S.; writing一review and editing, J.P.S., M.A.B. and H.M.H. All authors have read and agreed to the published version of the manuscript.

Funding: This research was partially funded by NOAA's Global Ocean Monitoring and Observing Program via the Northern Gulf of Mexico Cooperative Institute managed by Mississippi State University (NOAA CPO FundRef number 100007298 and NGI Grant No. 19-NGI3-70), and partially funded through NASA's support for the OVWST. It was also partially funded under the NGI Grant No. 18-NGI3-53 under NOAA Research Support Award NA16OAR4320199.

Acknowledgments: The authors recognize the NOAA/AOML/Hurricane Research Division and Paul Reasor for granting access to the LF and TDR radar data, Risk Management Solutions HWind for permitting the utilization of their Quality Control Application, operational data platforms, and database to construct historical reanalysis products, and the Marine Data Center research group at the Center for Ocean-Atmospheric Prediction Studies (COAPS) for providing coding assistance.

Conflicts of Interest: The authors declare no conflict of interest. The funders had no role in the design of the study; in the collection, analyses, or interpretation of data; in the writing of the manuscript, or in the decision to publish the results.

\section{References}

1. Marks, F.D. Evolution of the Structure of Precipitation in Hurricane Allen (1980). Mon. Weather Rev. 1985, 113, 909-930. [CrossRef]

2. Stephens, G.L.; Kummerow, C.D. The Remote Sensing of Clouds and Precipitation from Space: A Review. J. Atmos. Sci. 2007, 64, 3742-3765. [CrossRef]

3. Holbach, H.M.; Uhlhorn, E.W.; Bourassa, M.A. Off-Nadir SFMR Brightness Temperature Measurements in High-Wind Conditions. J. Atmos. Ocean. Technol. 2018, 35, 1865-1879. [CrossRef] 
4. Lauknes, T.R. Rockslide Mapping in Norway by Means of Interferometric SAR Time Series Analysis. Ph.D. Thesis, University of Tromsø, Munin, Iceland, 18 March 2011.

5. Bourassa, M.A.; Meissner, T.; Cerovecki, I.; Chang, P.S.; Dong, X.; De Chiara, G.; Donlon, C.; Dukhovskoy, D.S.; Elya, J.; Fore, A.; et al. Remotely Sensed Winds and Wind Stresses for Marine Forecasting and Ocean Modeling. Front. Mar. Sci. 2019, 6, 443. [CrossRef]

6. Rodriguez, E.; Bourassa, M.A.; Chelton, D.; Farrar, J.T.; Long, D.; Perkovic-Martin, D.; Samelson, R. The Winds and Currents Mission Concept. Front. Mar. Sci. 2019, 6, 438. [CrossRef]

7. National Academies of Sciences, Engineering, and Medicine. Thriving on Our Changing Planet: A Decadal Strategy for Earth Observation from Space; The National Academies Press: Washington, DC, USA, 20 January 2019.

8. Barnes, C.E.; Barnes, G.M. Eye and Eyewall Traits as Determined with the NOAA WP-3D Lower-Fuselage Radar. Mon. Weather Rev. 2014, 142, 3393-3417. [CrossRef]

9. Willoughby, H.E.; Clos, J.A.; Shoreibah, M.G. Concentric Eye Walls, Secondary Wind Maxima, and The Evolution of the Hurricane vortex. J. Atmos. Sci. 1982, 39, 395-411. [CrossRef]

10. Senn, H.V.; Hiser, H.W. On the Origin of Hurricane Spiral Rainbands. J. Meteorol. 1959, 16, 419-426. [CrossRef]

11. Kepert, J.D. The Boundary Layer Dynamics of Tropical Cyclone Rainbands. J. Atmos. Sci. 2018, 75, 3777-3795. [CrossRef]

12. Barnes, G.M.; Zipser, E.J.; Jorgensen, D.; Marks, F., Jr. Mesoscale and Convective Structure of a Hurricane Rainband. J. Atmos. Sci. 1983, 40, 2125-2137. [CrossRef]

13. Barnes, G.M.; Stossmeister, G.J. The Structure and Decay of a Rainband in Hurricane Irene (1981). Mon. Weather Rev. 1986, 114, 2590-2601. [CrossRef]

14. Chelton, D.B.; Schlax, M.G.; Samelson, R.M.; Farrar, J.T.; Molemaker, M.J.; McWilliams, J.C.; Gula, J. Prospects for future satellite estimation of small-scale variability of ocean surface velocity and vorticity. Prog. Oceanogr. 2018, 173, 256-350. [CrossRef]

15. Ardhuin, F.; Brandt, P.; Gaultier, L.; Donlon, C.; Battaglia, A.; Boy, F.; Casal, T.; Chapron, B.; Collard, F.; Cravatte, S.; et al. SKIM, a Candidate Satellite Mission Exploring Global Ocean Currents and Waves. Front. Mar. Sci. 2019, 6, 209. [CrossRef]

16. Draper, D.W.; Long, D. Evaluating the effect of rain on SeaWinds scatterometer measurements. J. Geophys. Res. Space Phys. 2004, 109, 1-12. [CrossRef]

17. Jorgensen, D.; Willis, P. A Z-R relationship for hurricanes. J. Appl. Meteorol. 1982, 21, 356-366. [CrossRef]

18. Radar Lower Fuselage Sweep Format. Available online: https:/www.aoml.noaa.gov/hrd/format/ lfsweepfileformat.html (accessed on 21 March 2020).

19. Reasor, P.D.; Montgomery, M.T.; Marks, F.D.; Gamache, J.F. Low-Wavenumber Structure and Evolution of the Hurricane Inner Core Observed by Airborne Dual-Doppler. Mon. Weather Rev. 2014, 128, 1653-1680. [CrossRef]

20. Irma 2017 Radar Data. Available online: https://www.aoml.noaa.gov/hrd/Storm_pages/irma2017/radar.html (accessed on 29 March 2020).

21. Awaka, J.; Le, M.; Chandrasekar, V.; Yoshida, N.; Higashiuwatoko, T.; Kubota, T.; Iguchi, T. Rain Type Classification Algorithm Module for GPM Dual-Frequency Precipitation Radar. J. Atmos. Ocean. Technol. 2016, 33, 1887-1898. [CrossRef]

22. Jiang, H.; Black, P.G.; Zipser, E.J.; Marks, F.D.; Uhlhorn, E.W. Validation of rain-rate estimation in hurricanes from the stepped frequency microwave radiowave: Algorithm correct and error analysis. J. Atmos. Sci. 2006, 63, 252-267. [CrossRef]

23. Marshall, J.S.; Langille, R.C.; Palmer, W.M.K. Measurement of rainfall by radar. J. Meteorol. 1947, 4, $186-192$. [CrossRef]

24. Wexler, R.; Atlas, D. Radar reflectivity and attenuation of rain. J. Appl. Meteorol. 1963, 2, 276-280. [CrossRef]

25. Olsen, R.; Rogers, D.; Hodge, D. The $\mathrm{aR}^{\mathrm{b}}$ relation in the calculation of rain attenuation. IEEE Trans. Antennas Propag. 1978, 26, 318-329. [CrossRef]

26. Ulaby, F.; Long, D.G. Microwave Radar and Radiometric Remote Sensing, 1st ed.; University of Michigan Press: Ann Arbor, MI, USA, 2014; p. 1111.

27. Battaglia, A.; Mroz, K.; Watters, D.; Ardhuin, F. GPM-Derived Climatology of Attenuation Due to Clouds and Precipitation at Ka-Band. IEEE Trans. Geosci. Remote Sens. 2020, 58, 1812-1820. [CrossRef] 
28. Ardhuin, F.; Chapron, B.; Maes, C. Satellite Doppler Observations for the Motions of the Oceans. Bull. Am. Meteorol. Soc. 2019, 100, ES215-ES219. [CrossRef]

29. Powell, M.D.; Houston, S.H.; Amat, L.R. The HRD real-time hurricane wind analysis system. J. Wind. Eng. Ind. Aerodyn. 1998, 77, 53-64. [CrossRef]

30. Remund, Q.P.; Long, D.G. A Decade of QuikSCAT Scatterometer Sea Ice Extent Data. IEEE Trans. Geosci. Remote Sens. 2014, 52, 4281-4290. [CrossRef]

31. Bourassa, M.; McBeth-Ford, K. Uncertainty in scatterometer-derived vorticity. J. Atmos. Ocean. Technol. 2010, 27, 594-603. [CrossRef]

32. Rodriguez, E. On the optimal design of Doppler scatterometers. Remote Sens. 2018, 10, 1765. [CrossRef]

33. Uhlhorn, E.W.; Black, P.G. Verification of Remotely Sensed Sea Surface Winds in Hurricanes. J. Atmos. Ocean. Technol. 2003, 20, 99-116. [CrossRef]

(C) 2020 by the authors. Licensee MDPI, Basel, Switzerland. This article is an open access article distributed under the terms and conditions of the Creative Commons Attribution (CC BY) license (http://creativecommons.org/licenses/by/4.0/). 